Article

\title{
Photocatalytic Nanofiltration Membrane Using Zr-MOF/GO Nanocomposite with High-Flux and Anti-Fouling Properties
}

\author{
Rina Heu ${ }^{1,2}$, Mohamed Ateia ${ }^{3, *(1)}$ and Chihiro Yoshimura ${ }^{1}$ \\ 1 Department of Civil and Environmental Engineering, Tokyo Institute of Technology, 2-12-1-M1-4 Ookayama, \\ Tokyo 152-8552, Japan; heu.r.aa@m.titech.ac.jp (R.H.); yoshimura.c.aa@m.titech.ac.jp (C.Y.) \\ 2 Faculty of Hydrology and Water Resources Engineering, Institute of Technology of Cambodia, \\ Phnom Penh 12156, Cambodia \\ 3 Department of Chemistry, Northwestern University, Evanston, IL 60208, USA \\ * Correspondence: ateia@northwestern.edu; Tel.: +1-864-650-8173
}

Received: 12 June 2020; Accepted: 24 June 2020; Published: 25 June 2020

check for updates

\begin{abstract}
Photocatalytic nanofiltration (NF) membranes with enhanced flux and anti-fouling properties were prepared from a layered in situ nanocomposite of metal organic framework (i.e., UiO-66) and graphene oxide (UiO-66_GO) on a polyamide NF membrane using a pressure-assisted self-assembly method. For filtering pure water and humic acid, the composite membrane with a $10 \%$ UiO-66_GO loading (UiO-66_GO/NF-10\%) showed a higher water flux (up to $63 \mathrm{~kg} / \mathrm{m}^{2} \mathrm{~h}$ bar), flux recovery (80\%), and total fouling resistance (33\%) than the pristine NF membrane. Physical and chemical characterization revealed that this performance was attributed to improvements in hydrophilicity, porosity, surface smoothness, and charge repulsion. The UiO-66_GO/NF-10\% composite membrane exhibited better physical stability with a relatively low mass loss (8.64\%) after five washes than the membranes with mass loadings of 5 and $15 \mathrm{wt} \%$. Furthermore, the UiO-66_GO/NF-10\% composite membrane exhibited considerable photocatalytic activity under ultraviolet (UV) irradiation (bandgap: $3.45 \mathrm{eV}$ ), which reduced irreversible fouling from $20.7 \%$ to $2.4 \%$ and increased flux recovery to $98 \%$. This study demonstrated that surface modification with the UiO-66_GO nanocomposite produced a high-flux anti-fouling photocatalytic NF membrane, which is promising for water purification.
\end{abstract}

Keywords: graphene oxide; metal-organic framework; nanofiltration; pharmaceuticals; photocatalysis; UiO-66

\section{Introduction}

Nanofiltration (NF), which was introduced in the late 1980s, has a high removal efficiency for hardness, multivalent ions, heavy metal, and organic molecules (e.g., micropollutants and dyes) [1,2]. Thus, NF can be used as a final process in water treatment trains to produce high-quality drinking water and it is used in several countries. For instance, high supply capacity has been achieved in water treatment plants in the USA $\left(152,000 \mathrm{~m}^{3} / \mathrm{d}\right)$, France $\left(140,000 \mathrm{~m}^{3} / \mathrm{d}\right)$, Holland $\left(57,000 \mathrm{~m}^{3} / \mathrm{d}\right)$, Spain $\left(30,000 \mathrm{~m}^{3} / \mathrm{d}\right)$, and England $\left(30,000 \mathrm{~m}^{3} / \mathrm{d}\right)$ [3]. One of the best examples of the use of NF is in the Mery Sur Oise plant in northern Paris, which has used NF since 1999 to remove pesticides and other organic pollutants [4,5].

Inorganic and polymeric membranes are used in most NF membrane treatments [6]. Inorganic membranes have the advantages of a stable pore structure, chemical inertness, and temperature 
resistance, although their disadvantages include complicated fabrication processes, non-selective cracks, and high cost [7]. In contrast, polymeric membranes have dominated the membrane market due to their simple, inexpensive fabrication [8], although their hydrophobic surfaces and flexibility result in limited water flux and fouling [9]. Thus, NF membranes could be improved by integrating them with hydrophilic materials to improve their flux and anti-fouling properties.

A new class of highly porous hydrophilic materials with a zirconium-based metal-organic framework improves water flux in membranes [10]. In particular, the material called UiO-66 can be integrated into a membrane, and the integrated membrane shows good membrane stability, high resilience to mechanical stress, and wide applicability [11]. This is because the organic linker in UiO-66 provides a platform for chemical modifications of its surface, which allows better adhesion to polymeric membranes than other inorganic materials [12]. However, the agglomeration and aggregation of UiO-66 particles on the membrane surface tend to decrease the smoothness of the membrane surface and block the membrane pores, reducing water flux [13]. In situ growth of UiO-66 particles on a two-dimensional graphene oxide (GO) sheet demonstrated that the GO oxygen functional groups improved UiO-66 formation while increasing the dispersion force among UiO-66 particles and suppressing their aggregation, allowing their physicochemical properties such as morphology, size, and structure to be controlled [14-16]. In addition, a membrane integrated with an in situ UiO-66 and GO (UiO-66_GO) nanocomposite showed higher flux and anti-fouling properties compared with the pristine polyethersulfone membrane because of its high hydrophilicity and the smoothness of the membrane surface [10].

However, the in situ UiO-66_GO nanocomposite has been applied only to ultrafiltration membranes and their performance has only been tested for removing macromolecule compounds, such as natural organic matter [10]. The use of in situ UiO-66_GO nanocomposites on an NF membrane has not been reported, and thus the membrane synthesis method, water flux, anti-fouling properties, and rejection of organic micropollutants (OMPs) of these composite membranes need to be investigated. Furthermore, the photocatalytic activity of the UiO-66_GO nanocomposite—as reported in our recent study [16]—may remove foulants without backwash. Membrane fouling is a major challenge for NF because it occurs on the nanoscale [17,18]. Thus, integrating the UiO-66_GO nanocomposite may allow total control of fouling and increase the stability and lifetime of the membrane, which would reduce the operational and maintenance costs of membrane treatment. However, the use of photocatalysis to maintain or regenerate fouled composite membranes has not been explored.

In this work, we developed photocatalytic NF membranes by modifying the hydrophobic surface of an NF membrane with a hydrophilic UiO-66_GO nanocomposite to improve the water flux and anti-fouling properties. We demonstrated a synthesis method for the composite NF membranes, and for the membrane with 10\% UiO-66_GO loading, we examined the stability, OMP rejection, and the recovery of the fouled membrane by ultraviolet (UV) photocatalysis.

\section{Results and Discussion}

\subsection{Characterization of Metal Organic Framework and Graphene Oxide (UiO-66_GO) Nanocomposite and Membranes}

Scanning electron microscopy (SEM) and transmission electron microscopy (TEM) images confirmed that the dispersion of UiO-66 particles on the GO sheet was uniform (Figure 1). The dispersion of the UiO-66_GO nanocomposite was explained by the coordination of the $\mathrm{Zr}^{4+}$ metal nodes of UiO-66 by functional groups on the GO sheet, suppressing the aggregation of UiO-66 [19]. This observation indicates that the in situ hydrothermal synthesis of UiO-66_GO nanocomposite dispersed UiO-66 uniformly on the GO layers rather than forming a physical mixture, which is consistent with Ma et al. (2017). The structure of the UiO-66_GO nanocomposite may prevent GO layer stacking, which is advantageous for membrane 
filtration. In addition, the Fourier-transform infrared (FTIR) spectrum of the UiO-66_GO nanocomposite showed peaks for surface functional groups, including for the $\mathrm{Zr}-\mathrm{O}$ mode, $\mathrm{Zr}-\mathrm{O}-\mathrm{C}$ symmetric stretching, the $\mathrm{C}=\mathrm{C}$ bond of the benzene ring, the $\mathrm{O}-\mathrm{C}-\mathrm{O}$ moiety of the 1,4-benzenedicarboxylic (BDC) acid ligand, the $\mathrm{C}=\mathrm{O}$ bond of the carboxyl groups of the $\mathrm{BDC}$ acid ligand, and $\mathrm{O}-\mathrm{H}$ bonds of the hydroxyl groups (Figure 2). The presence of oxygen hydrophilic functional groups (i.e., $\mathrm{O}-\mathrm{C}-\mathrm{O}, \mathrm{C}=\mathrm{O}, \mathrm{O}-\mathrm{H}$ ) indicated that the UiO-66_GO nanocomposite was hydrophilic. The band gaps of UiO-66 and UiO-66_GO nanocomposite were 3.55 and $3.45 \mathrm{eV}$, respectively, showing that GO narrowed the band gap of UiO-66. Further details of the properties of GO, UiO-66, and the UiO-66_GO composite are reported in our previous article [16].
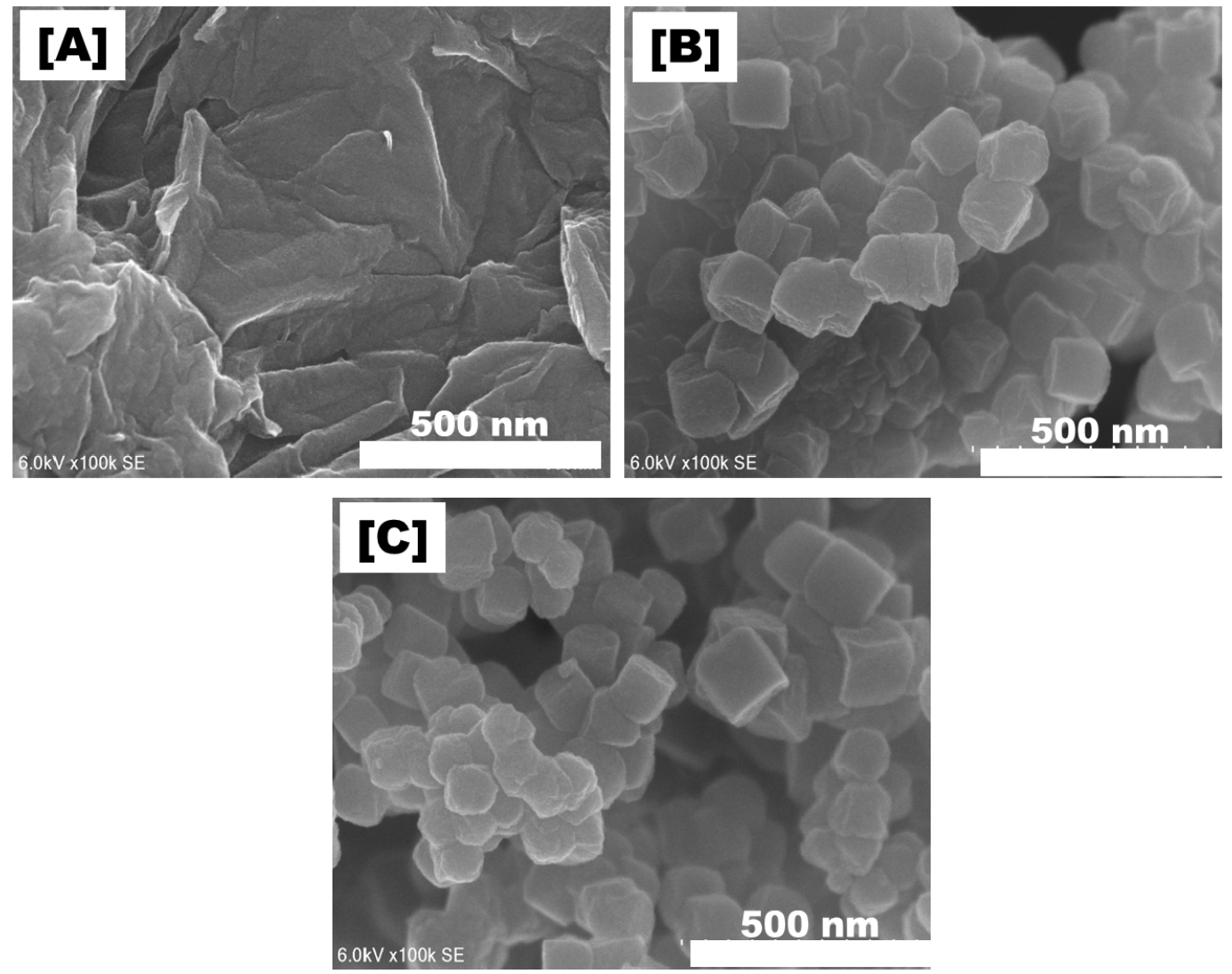

Figure 1. Scanning electron microscope (SEM) images of (A) graphene oxide (GO), (B) metal organic framework (UiO-66), and (C) the UiO-66_GO composite.

SEM revealed the rough surface of the pristine NF membrane, which contained many nodules and globules on its surface (Figure 3A), similar to previously reported polyamide membranes [20,21]. The deposition of the UiO-66_GO nanocomposite on the NF membrane created the smooth surface (Figure 3B-D), possibly because the nodules were covered by UiO-66_GO sheets. In addition, the SEM images showed that the surface morphology depended on the UiO-66_GO content. Some areas of the UiO-66_GO/NF-5\% membrane were not completely covered by UiO-66_GO (red circle in Figure 3B), whereas the UiO-66_GO/NF-10\% membrane showed a homogenous surface without uncovered areas or cracks (Figure 3C). The UiO-66_GO/NF-15\% membrane showed some cracks (Figure 3D), indicating that a UiO-66_GO content higher than 10\% decreased the stability of the composite membrane. 


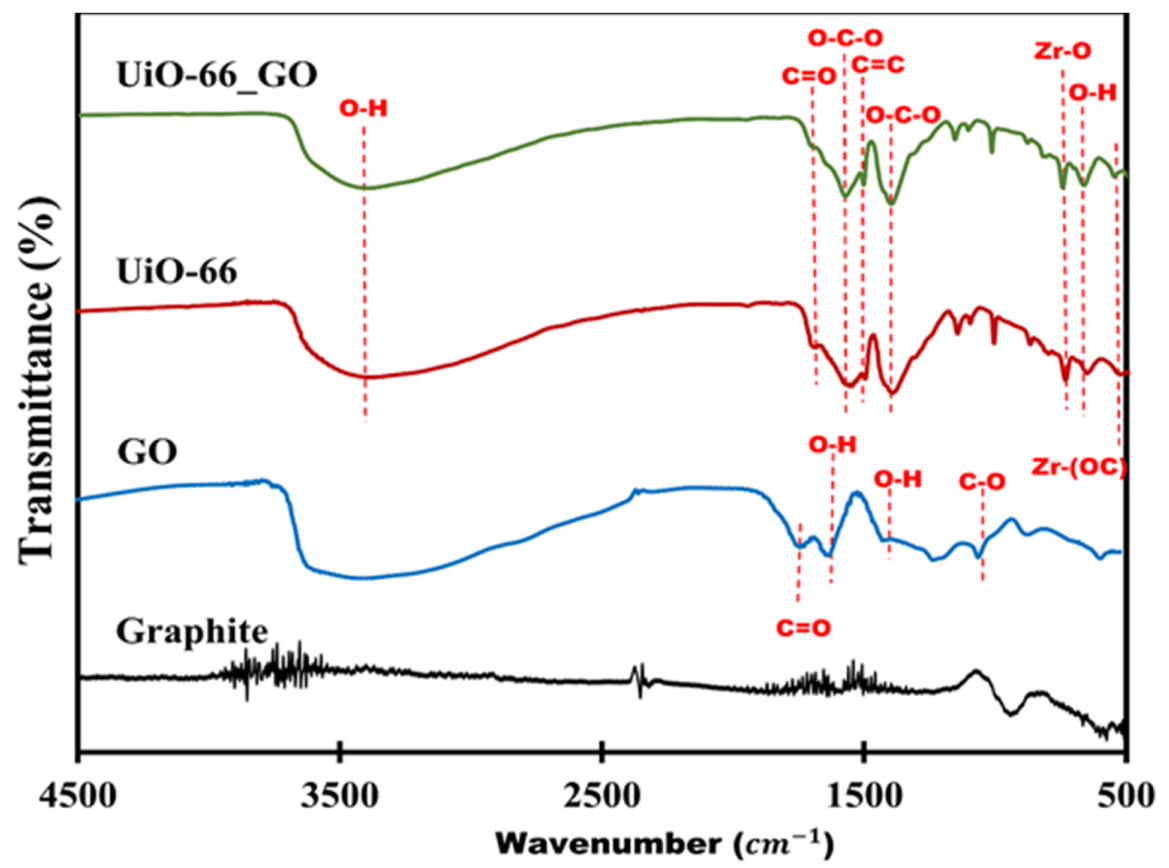

Figure 2. Fourier-transform infrared (FTIR) spectra of graphite, GO, UiO-66, and the UiO-66_GO nanocomposite.
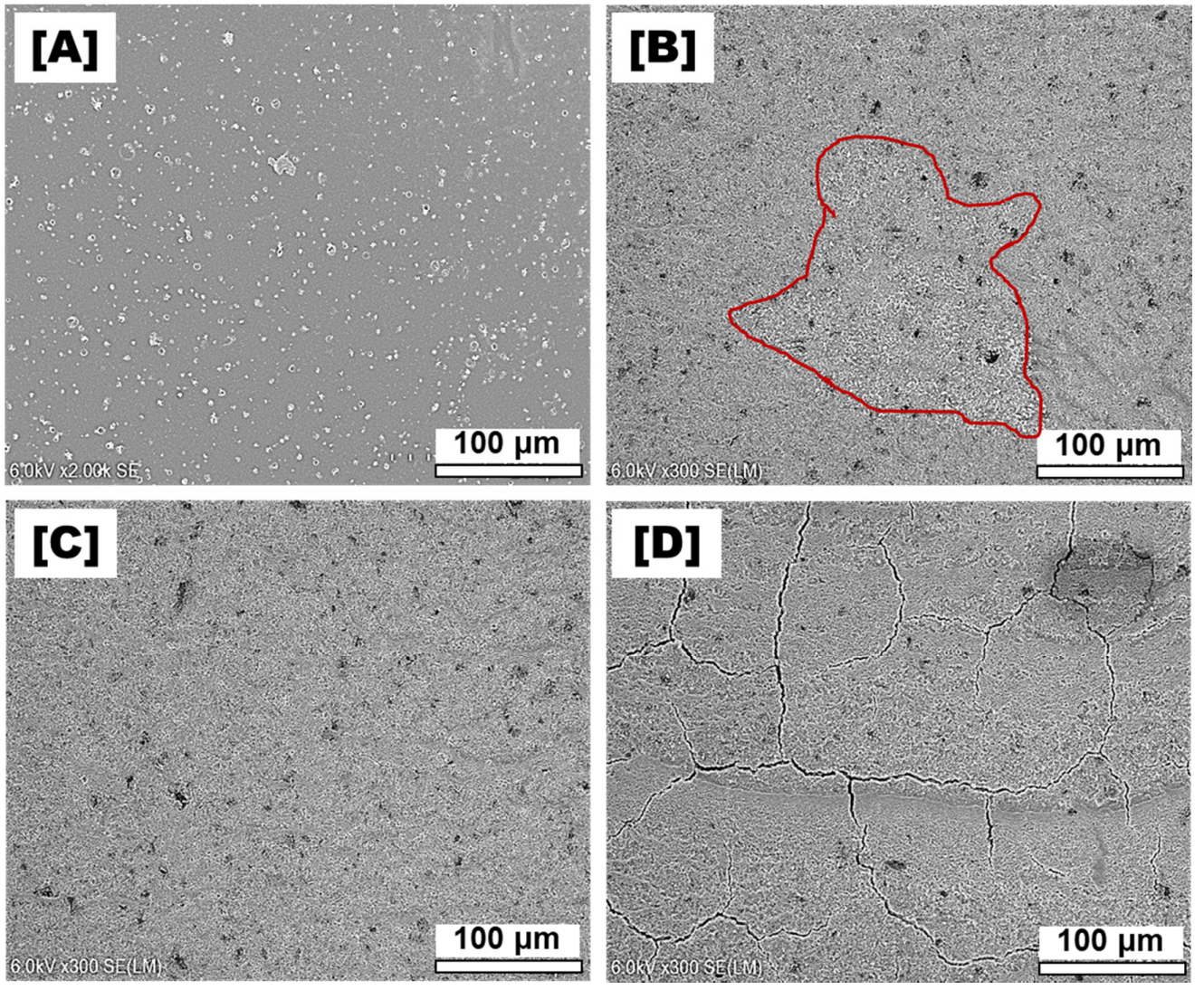

Figure 3. SEM images of the (A) pristine nanofiltration (NF) membrane, and the composite membranes with UiO-66_GO loadings of (B) 5\%, (C) 10\%, and (D) 15\%. 
The roughness parameters showed that the roughness of all the composite membranes was lower than that of the pristine NF membrane due to the presence of the UiO-66_GO sheets (Figure 4, Table 1). The UiO-66_GO sheets covered the rough membrane surface, possibly by hydrogen bonding between the functional groups of the UiO-66_GO nanocomposite and the surface layer of the polyamide membrane $[10,22]$. Consequently, unlike other inorganic nanoparticles, which typically show aggregation [23,24], the UiO-66_GO nanocomposite was uniformly distributed on the membrane surface, increasing the surface smoothness. A similar modification has been reported by other studies in which hydrophilic materials were loaded on polyamide membranes [20,22,25,26]. In addition, pressure-assisted self-assembly (PASA) at a constant pressure of 5 bar may produce tighter, denser, and smoother membranes than physical mixing of UiO-66 and GO. Increasing the UiO-66_GO nanocomposite loading to 15\% gave higher roughness parameters (average roughness $\left[S_{\mathrm{a}}\right]$ and root mean square roughness $\left[S_{\mathrm{q}}\right]$ ) than loadings of $5 \%$ and $10 \%$ because of the aggregation and agglomeration of UiO-66_GO particles on the membrane surface.

Table 1. Characterization of the pristine and composite membranes.

\begin{tabular}{|c|c|c|c|c|c|c|c|}
\hline \multirow[b]{2}{*}{ Membrane } & \multirow{2}{*}{$\begin{array}{l}\text { Thickness } \\
\text { mm }\end{array}$} & \multirow{2}{*}{ Porosity \% } & \multirow{2}{*}{$\begin{array}{c}\text { Mean Pore Size } \\
\text { nm }\end{array}$} & \multicolumn{3}{|c|}{ Roughness Parameters } & \multirow{2}{*}{$\begin{array}{c}\text { Contact Angle } \\
\text { Deg }\end{array}$} \\
\hline & & & & $\begin{array}{c}S_{\mathrm{a}} \\
\mathrm{nm}\end{array}$ & $\begin{array}{c}S_{\mathrm{q}} \\
\mathrm{nm}\end{array}$ & $\underset{\mathrm{nm}}{S_{\mathrm{y}}}$ & \\
\hline Pristine NF & 0.252 & 64.8 & 2.78 & 217 & 283 & 1986 & 39.5 \\
\hline UiO-66_GO/NF-5\% & 0.267 & 72.1 & 2.98 & 161 & 211 & 1723 & 22.7 \\
\hline UiO-66_GO/NF-10\% & 0.275 & 76.4 & 3.26 & 122 & 161 & 1564 & 14.2 \\
\hline UiO-66_GO/NF-15\% & 0.310 & 78.3 & 3.51 & 136 & 176 & 1442 & 5.63 \\
\hline
\end{tabular}

$S_{\mathrm{a}}$ : average roughness; $S_{\mathrm{q}}$ : root mean square roughness; $S_{\mathrm{y}}$ : mean height difference between the highest peaks and lowest valleys.

The pristine NF membrane showed a water contact angle of $39.5^{\circ}$ (Table 1, Figure S2). Addition of $5 \%, 10 \%$, and 15\% UiO-66_GO nanocomposite to the NF membrane surface decreased the water contact angles to $22.7^{\circ}, 14.2^{\circ}$, and $5.63^{\circ}$, respectively (Table 1, Figure S2). This means that the presence of hydrophilic functional groups $(\mathrm{O}-\mathrm{C}-\mathrm{O}, \mathrm{C}=\mathrm{O}$, and $\mathrm{O}-\mathrm{H})$ on the UiO-66_GO surface resulted in the higher hydrophilicity and wettability of the membrane, which improve filtration and anti-fouling performance.

The overall porosity and the mean pore radius of the pristine NF were $64.8 \%$ and $2.78 \mathrm{~nm}$, respectively (Table 1). The addition of 5\%, 10\%, and 15\% UiO-66_GO to the NF membrane increased the overall porosities to $72.1 \%, 76.4 \%$, and $78.3 \%$, respectively (Table 1 ). The composite membranes also showed higher mean pore radii $(2.98,3.26$, and $3.51 \mathrm{~nm}$, respectively) compared with the pristine NF membrane $(2.78 \mathrm{~nm})$. The higher porosity and larger pore radius of the composite membrane explained why UiO-66_GO on the membrane did not block the membrane pores and water pathway. These properties were achieved by the in situ one-step hydrothermal method, and thus the composites possessed high porosity at the micro- and macropore levels, as confirmed previously [16].

\subsection{Filtration Performance}

\subsubsection{Water Flux}

The pristine NF membrane had a water flux of $34 \mathrm{~kg} / \mathrm{m}^{2} \mathrm{~h}$ bar (Figure 5), which was comparable to the reported range (1.5-30 kg/m² $\mathrm{h}$ bar) [27]. The water fluxes of the UiO-66_GO/NF-5\%, UiO-66_GO/NF-10\%, and UiO-66_GO/NF-15\% membranes were 44,57 , and $63 \mathrm{~kg} / \mathrm{m}^{2} \mathrm{~h}$ bar, respectively (Figure 5). This result demonstrated that modifying the NF surface with the UiO-66_GO-0.5 nanocomposite increased the water flux of the pristine NF membrane substantially owing to the increase of the surface hydrophilicity (water contact angle), porosity, and membrane pore size (Table 1). The increased membrane hydrophilicity 
was attributed to the oxygen-containing functional groups, such as hydroxyl and carboxyl, on the UiO-66_GO nanocomposite, which increased the water permeability and wettability of the membrane by attracting water molecules and the high water-holding capacity of these groups [7,28]. In addition, the higher porosity and larger pore size of the membranes improved the water transport paths and decreased the resistance to water molecules [22,29], increasing the water flux.
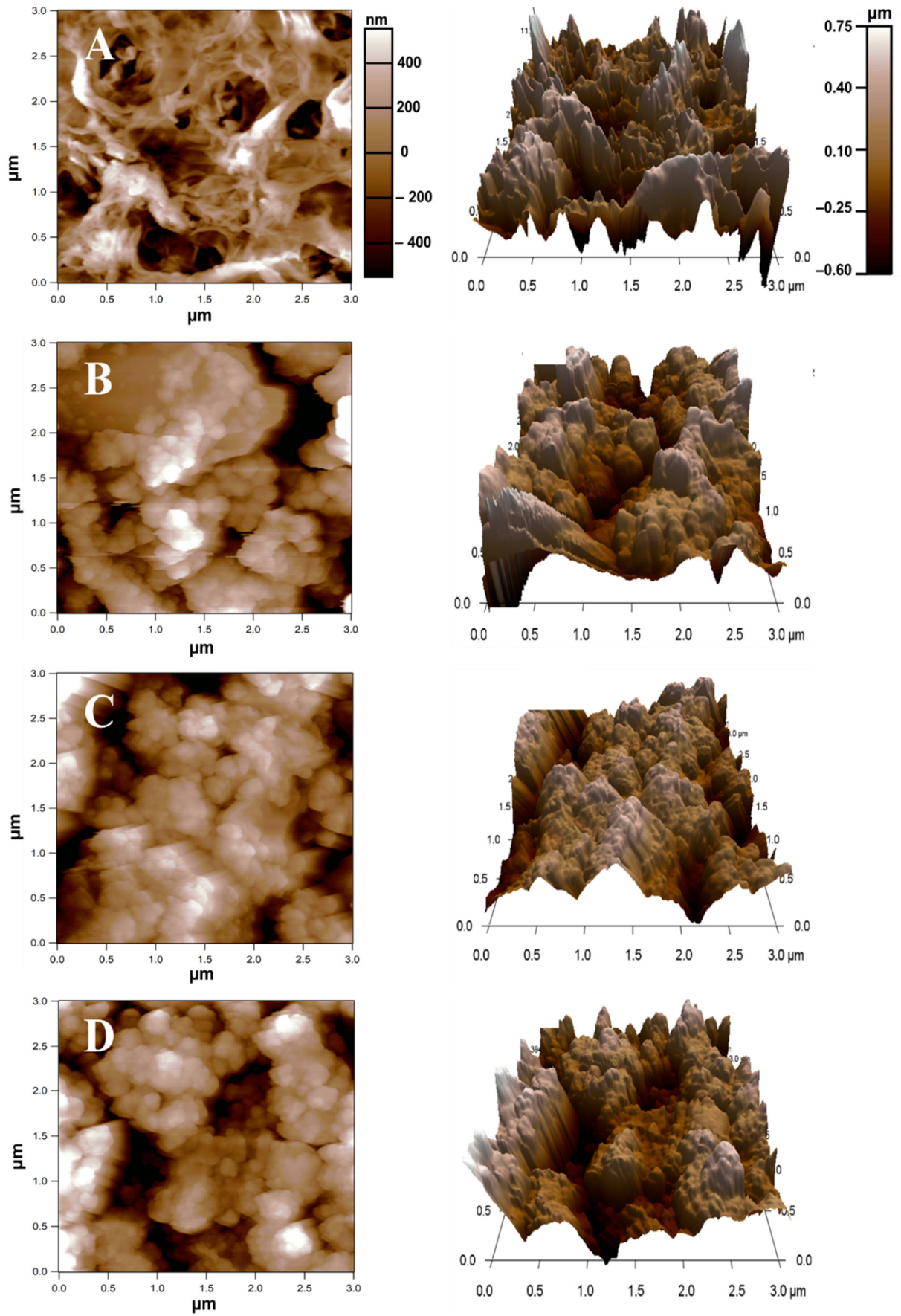

Figure 4. Two- and three-dimensional atomic force microscopy (AFM) images of (A) the pristine NF membrane, and the composite membranes with UiO-66_GO loadings of (B) 5\%, (C) 10\%, and (D) 15\%. 


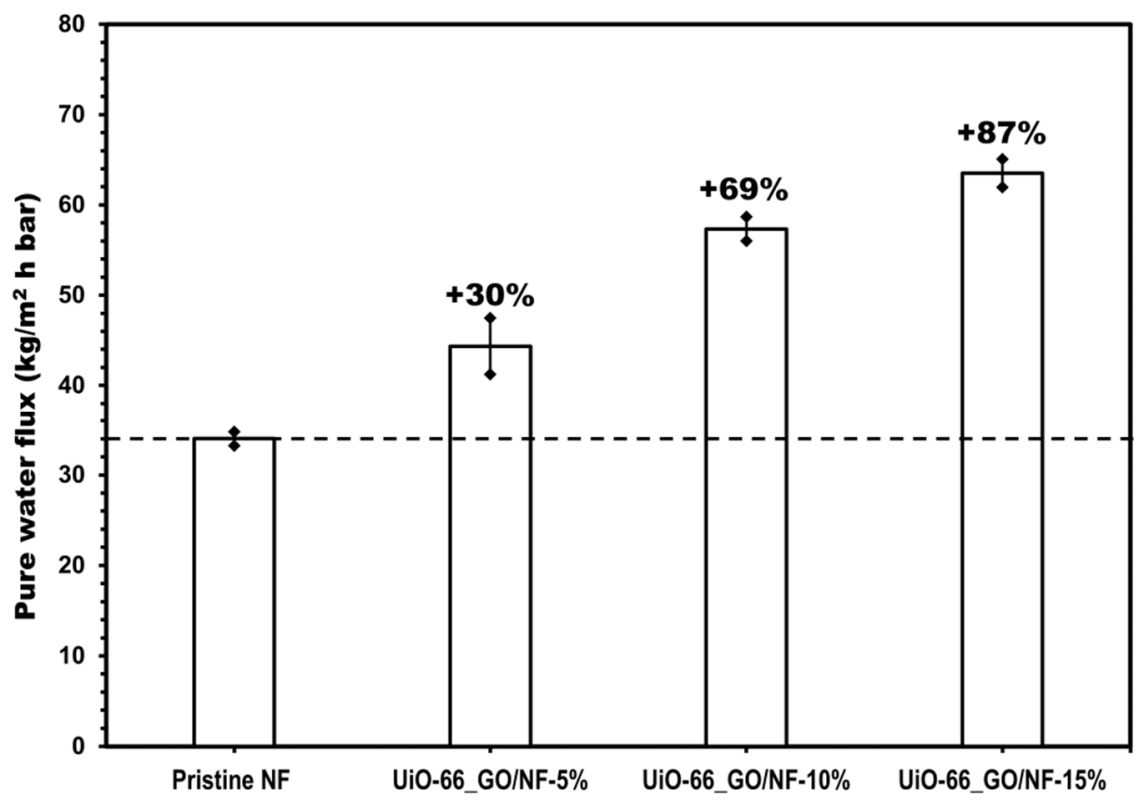

Figure 5. Pure water flux of pristine and composite membranes (operation pressure $=4$ bar; solution $\mathrm{pH}=5$ ). Plots and error bars represent averages and standard deviations from triplicate experiments.

\subsubsection{Membrane Stability}

The mass losses for UiO-66_GO loadings of 5 and $10 \mathrm{wt} \%$ after five washes were $4.49 \%$ and $8.64 \%$, respectively (Figure 6, Figure S3A,B). Both loading rates allowed the strong adhesion of the UiO-66_GO nanocomposite to the membrane surface. The terephthalic ligand and various functional groups on the UiO-66_GO nanocomposite provide a supporting platform for the surface chemical modifications, which allows substantial adhesion to the polyamide membrane [11,12]. However, when the UiO-66_GO loading was increased to $15 \mathrm{wt} \%$, the mass loss increased to $23.1 \%$, and voids were visible on the washed membranes (Figure 6, Figure S3A,B). SEM images showed many cracks on the as-prepared membrane surface, suggesting that the stability reduction was due to the poorly structured nanocomposite layer (Figure 3D). Because of the high water flux and good adhesion, we considered $10 \mathrm{wt} \%$ loading as the optimum and used it in subsequent experiments.

\subsubsection{Anti-Fouling Properties}

MilliQ water was replaced with Suwannee River humic acid (SRHA) solution, and the permeate flux of pristine and composite membranes decreased constantly (Figure 7A) due to SRHA molecules accumulating on the membrane surface [20,28]. After filtering SRHA solution for $180 \mathrm{~min}$ and washing with MilliQ water, the membranes were used to filter MilliQ water again, and the permeate flux was higher than for SRHA and stable over $1 \mathrm{~h}$. The pristine membrane showed a reduction in pure water flux from 34 to $15 \mathrm{~kg} / \mathrm{m}^{2} \mathrm{~h}$ bar, whereas the UiO-66_GO/NF membrane showed a reduction from 57 to $29 \mathrm{~kg} / \mathrm{m}^{2} \mathrm{~h}$ bar. The flux recovery ratio $(F R R)$, irreversible fouling ratio $\left(R_{\mathrm{ir}}\right)$, and total fouling ratio $\left(R_{\mathrm{t}}\right)$ of the pristine membrane were $49.9 \%, 49.8 \%$, and $57.3 \%$, respectively (Figure $7 \mathrm{~B}$ ). This result demonstrated that the adsorption of SRHA caused substantial irreversible fouling, accounting for almost $90 \%$ of the total fouling of the pristine membrane. In contrast, for the UiO-66_GO/NF membrane, FRR was increased to 79.6\% and $R_{\mathrm{t}}$ was decreased to $33.3 \%$. Furthermore, $R_{i r}$ was reduced to $20.7 \%$, which accounted for only $60 \%$ of $R_{\mathrm{t}}$, demonstrating that the nanocomposites prevented the adsorption of SRHA to the pristine membrane. For both pristine and composite membranes, the $R_{i r}$ values were higher than the $R_{r}$ values, implying that 
cake formation mainly contributed to fouling rather than concentration polarization. The higher FRR and lower fouling ratios of the UiO-66_GO/NF membrane than those of the pristine membrane further confirmed that the anti-fouling properties of the composite membrane arose from its hydrophilicity, surface roughness, and charge repulsion.

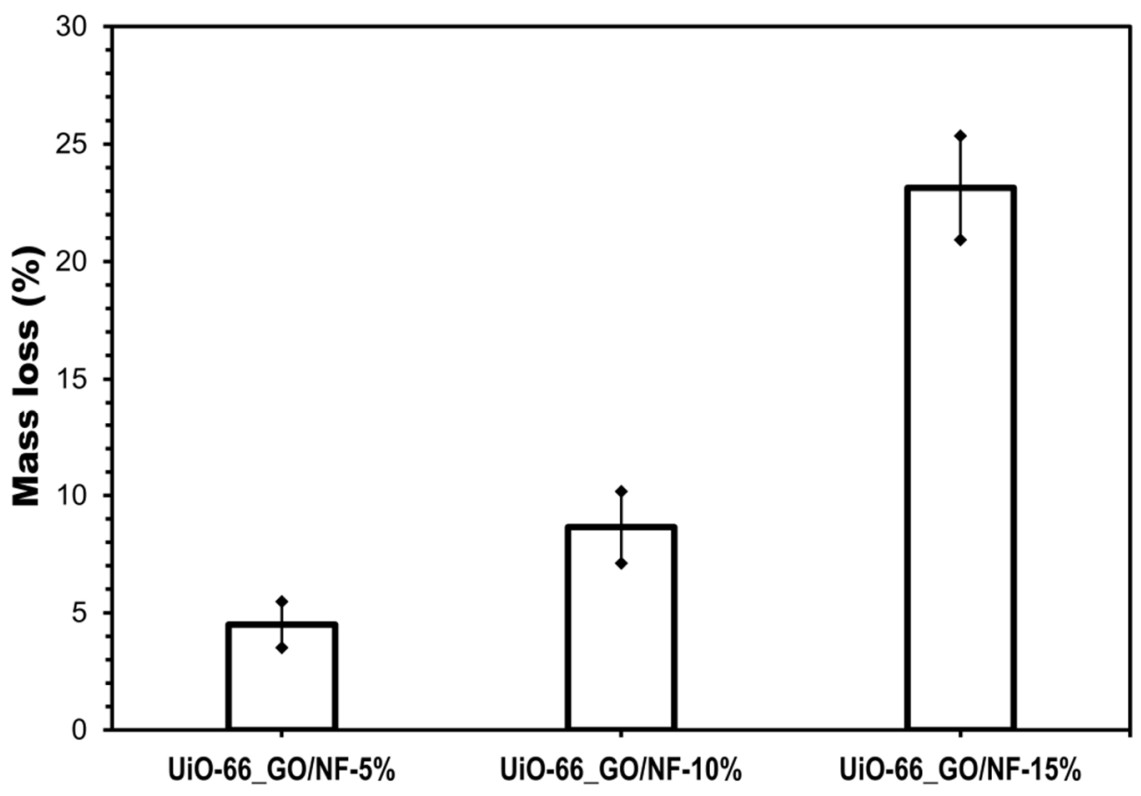

Figure 6. Mass loss (\%) of UiO-66_GO nanocomposites after five washes.

The hydrophilic character of the membrane made it less prone to fouling due to the abundance of hydrophilic functional groups, which decreases the adsorption of hydrophobic SRHA molecules on the membrane surface [30-32]. Furthermore, surface roughness promotes membrane fouling due to the accumulation of SRHA molecules in the deep valleys of the rough surface $[7,33]$. Thus, the lower surface roughness of the UiO-66_GO/NF membrane observed by atomic force microscopy (AFM) (Table 1, Figure 4) decreased membrane fouling compared with the pristine NF membrane. In addition, the membrane charge also affects its anti-fouling properties [34]. The pKa of SRHA is about 4.5 [35,36], meaning that SRHA had a negative charge under our experimental conditions of $\mathrm{pH}$ 5. The $\mathrm{pH}$ of the point of zero charge of UiO-66 and GO is about 4 [37-40], and thus the UiO-66_GO/NF membrane also had a negative charge at $\mathrm{pH}$ 5. Therefore, the electrostatic repulsion between the negative charges on the SRHA molecules and the membrane may be important in reducing the adhesion of SRHA to the membrane.

\subsubsection{Photocatalytic Activity of UiO-66_GO/Nanofiltration (NF) for Flux Recovery}

After the filtration of SRHA for $1 \mathrm{~h}, R_{i r}$ of the pristine and composite membranes were $49.8 \%$ and $20.7 \%$, respectively (Figure $8 \mathrm{~A}$ ). $R_{i r}$ was probably due to complete or partial blockage caused by the adsorption of SRHA to the membrane surface and pores [41,42]. After the fouled membrane was exposed to UV irradiation for $1 \mathrm{~h}, R_{i r}$ of the pristine membrane decreased slightly from $49.8 \%$ to $45.1 \%$, whereas $R_{i r}$ of the UiO-66_GO/NF membrane decreased substantially from $20.7 \%$ to only $2.4 \%$ (Figure 8A). The photocatalytic degradation of SRHA by the UiO-66_GO nanocomposite caused this large decrease in $R_{i r}$. To evaluate the effect of photocatalysis further, we measured FRR for the fouled membranes with and without irradiation (Figure 8B). FRR of the composite membrane after photodegradation increased by more than $18 \%$, which was higher than that of the pristine membrane (4\%). This result also suggested that under UV radiation, the composite membrane had substantial photocatalytic activity that degraded SRHA 
on the membrane surface and recovered water flux, resulting in the higher $F R R(>97 \%)$, compared with no UV irradiation (Figure 8B).
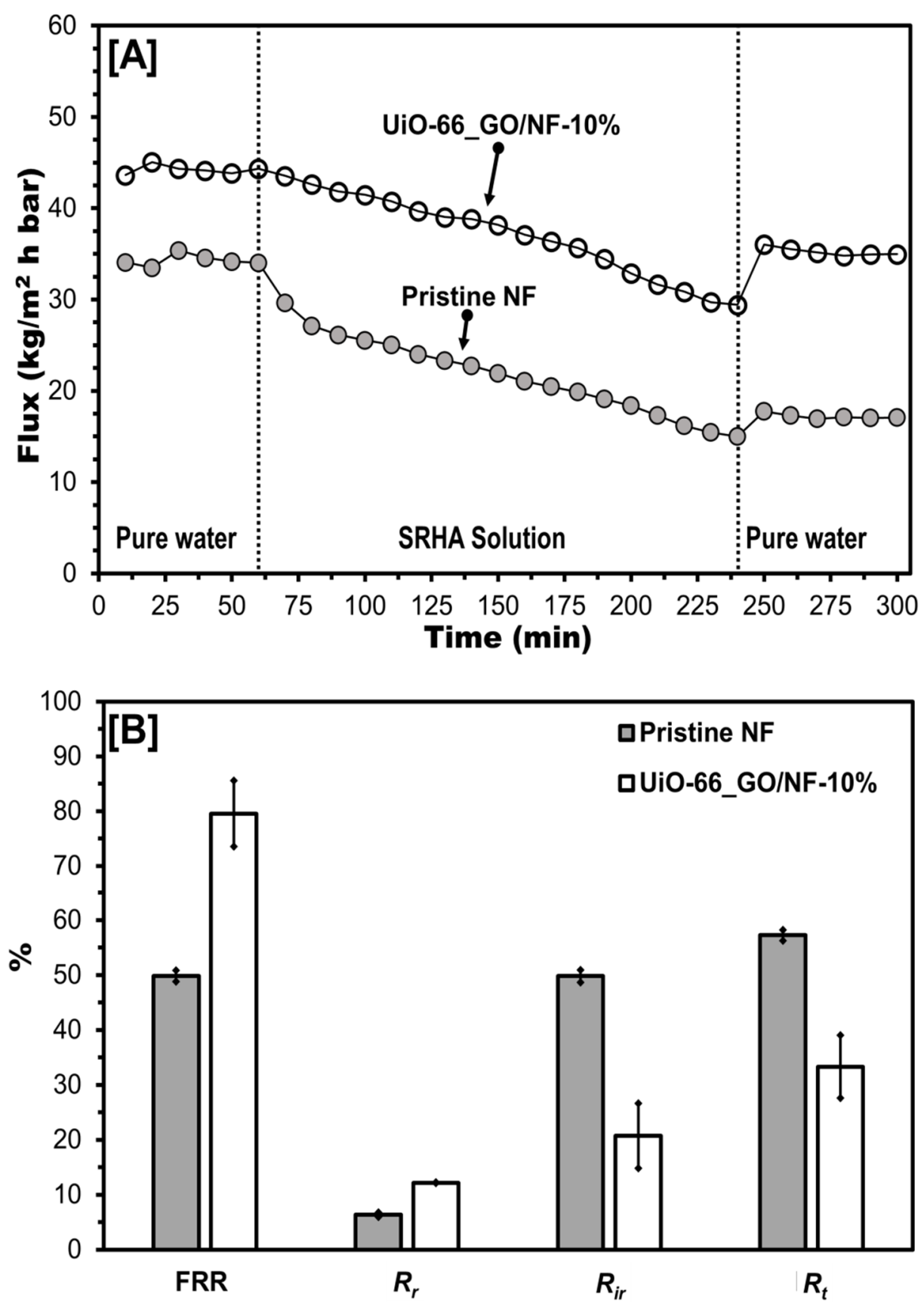

Figure 7. (A) Flux versus time and (B) flux recovery ratio and fouling ratios of the pristine NF and UiO-66_GO/NF-10\% membranes for Suwannee River humic acid (SRHA) filtration (experimental conditions: SRHA concentration $=50 \mathrm{mg} / \mathrm{L}$; operation pressure $=4$ bar; $\mathrm{pH}=5$ ). Plots and error bars represent averages and standard deviations from triplicate experiments. 

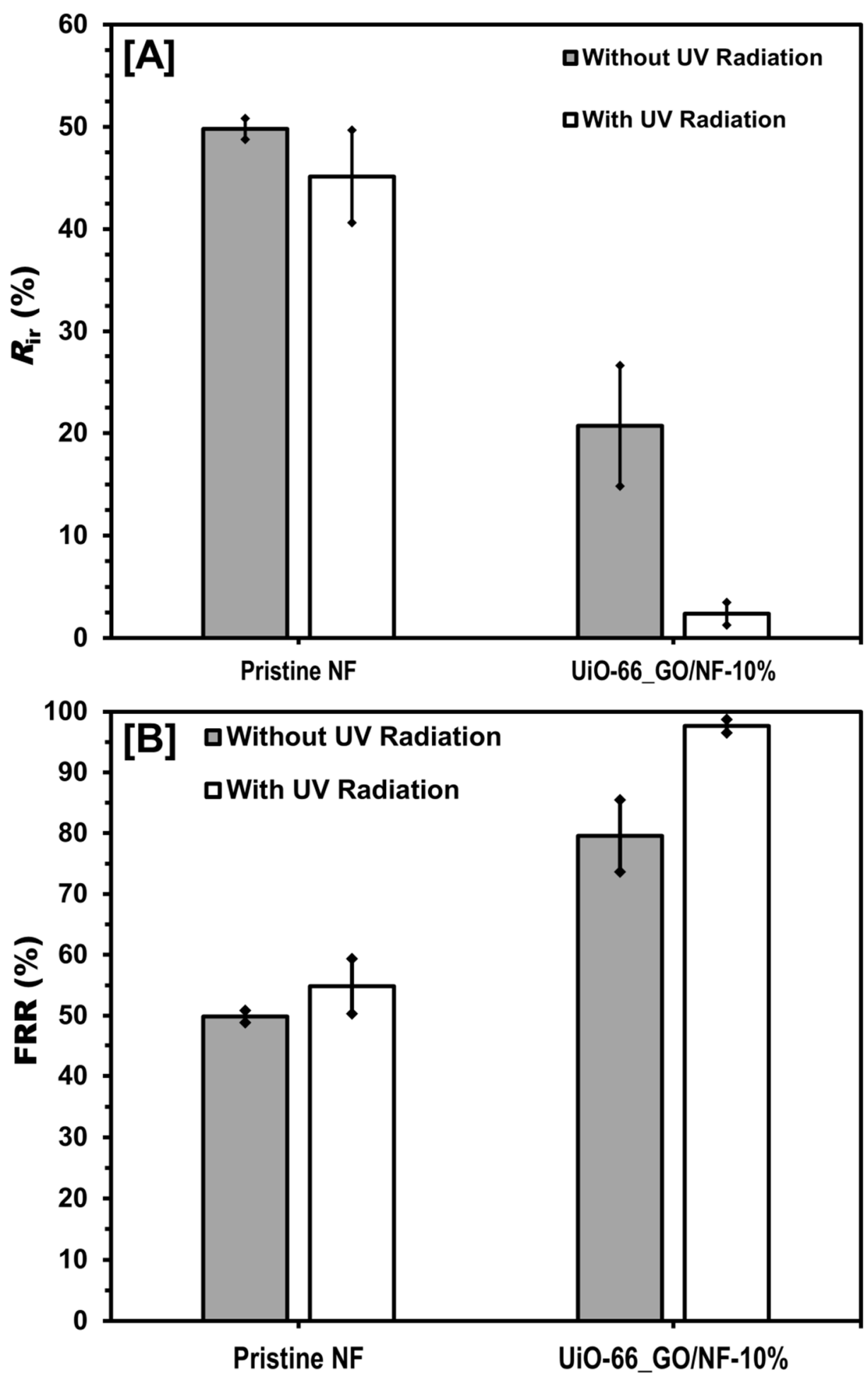

Figure 8. (A) $R_{i r}$ and (B) FRR with and without UV radiation for the pristine NF and UiO-66_GO/NF-10\% membranes after SRHA filtration. Plots and error bars represent the averages and standard deviations from triplicate experiments. 


\subsubsection{Separation Performance}

The separation of carbamazepine (CBZ) and diclofenac sodium (DCF) by the UiO-66_GO/NF-10\% membrane was examined. The initial removal rates were higher than $90 \%$ for the first 20 min of filtration (Figure 9), which may arise from the effect of CBZ and DCF adsorption on the membrane surface in addition to physical separation. Over a longer filtration time, the rejection decreased while the adsorption equilibrium was reached, and then became stable after $2 \mathrm{~h}$. The steady-state rejection of CBZ was $70 \%$, whereas that of DCF was still high at $93 \%$ (Figure 9).

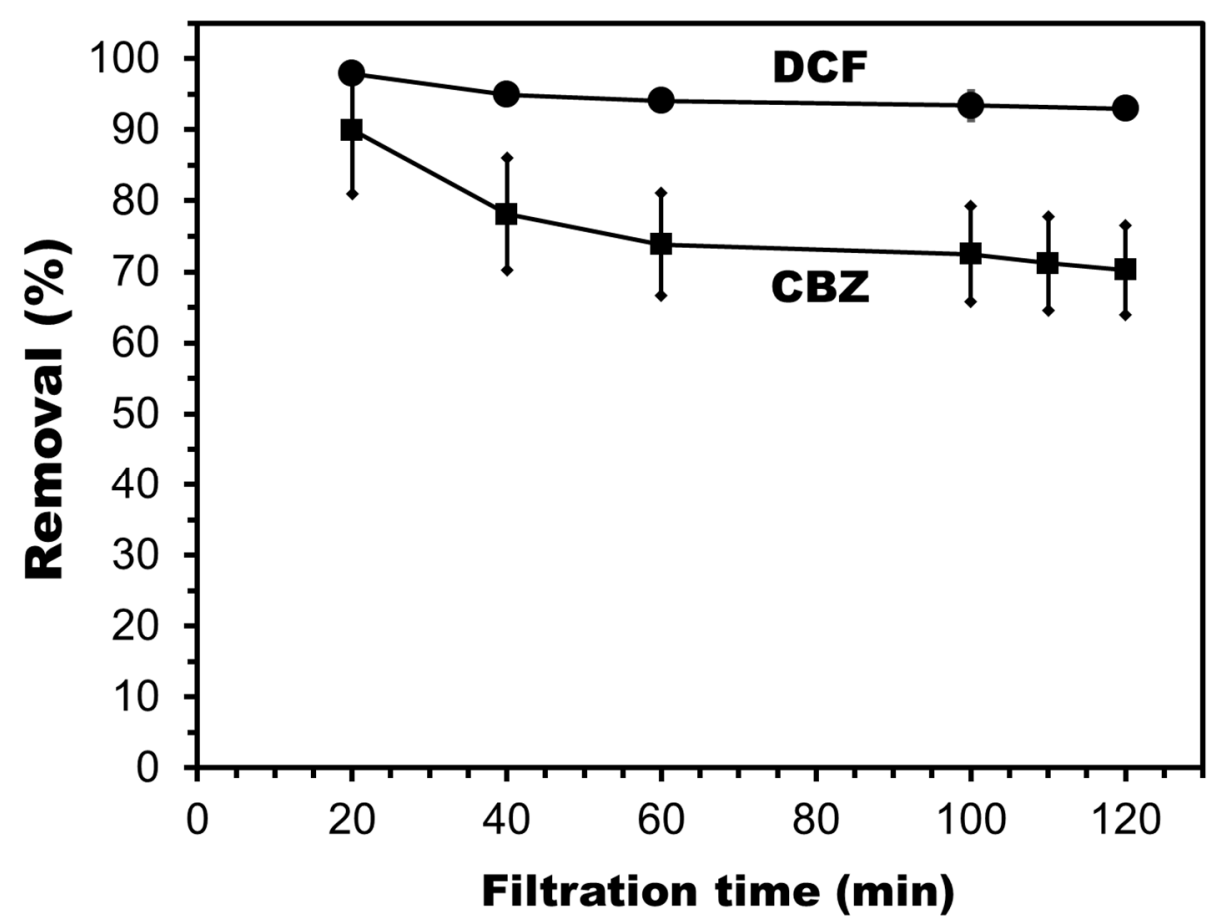

Figure 9. Diclofenac sodium (DCF) and carbamazepine (CBZ) removal over time by the UiO-66_GO/NF-10\% membrane (experimental conditions: initial DCF and CBZ concentration $=1 \mathrm{mg} / \mathrm{L}$; operation pressure $=4$ bar; solution $\mathrm{pH}=5$ ). Plots and error bars represent averages and standard deviations from duplicate experiments.

The molecular weight of DCF (296 Da) is higher than that of CBZ (236 Da), which may have contributed to the higher rejection efficiency of DCF via size exclusion. In addition, DCF and the UiO-66_GO nanocomposite had a negative charge at pH $5[39,40,43]$, which caused electrostatic repulsion between DCF molecules and the membrane surface, increasing the rejection of DCF, as described by Lin et al. (2017) [41]. In contrast, CBZ is charged positively at pH 5 [44,45], which allowed CBZ molecules to diffuse into the pores and the membrane surface, decreasing the rejection values [46]. Overall, UiO-66_GO/NF-10\% rejected both CBZ and DCF with high removal efficiency rates, which resulted from the combined effects of size exclusion (steric effects) and charge repulsion (Donnan effects).

\section{Materials and Methods}

\subsection{Materials}

CBZ $(>98 \%)$, DCF $(\leq 100 \%)$, hydrochloric acid $(35-37 \%)$, hydrogen peroxide (30-35.5\%), methanol $(99.9 \%)$, potassium permanganate $(>99.0 \%)$, sulfuric acid $(\geq 95 \%)$, terephthalic acid $(\geq 98 \%)$, and zirconium(IV) chloride $(>99.5 \%)$ were purchased from Sigma-Aldrich (Tokyo, Japan). 
$N, N^{\prime}$-Dimethylformamide (DMF; 99.5\%) was obtained from Kanto Chemical (Tokyo, Japan). Graphite flakes (325 mesh, 99.8\%) were purchased from Wako Chemical (Tokyo, Japan). SRHA was purchased from the International Humic Substances Society (Saint Paul, MN, USA). All chemical reagents were of analytical grade and were used without further purification. MilliQ water was used as a solvent for all experiments. Polyamide NF membrane sheet (molecular weight cut off 150-300 Da) was supplied by Synder (Sterlitech Corp, Kent, WA, USA) and a Millipore stirred cell (Amicon UFSC40001, Merck-Millipore, Burlington, MA, USA) was used for the filtration experiment.

\subsection{Preparation of UiO-66_GO Nanocomposite and Membranes}

GO and UiO-66 were prepared by the methods described by Heu et al. (2020). The hydrothermal UiO-66 preparation method was used to prepare the UiO-66_GO nanocomposite in the presence of GO. We used a $0.5 \%$ GO loading in the composite material because it showed the highest photodegradation rate for carbamazepine [16]. GO (10 mg) was dispersed in DMF $(150 \mathrm{~mL})$ and sonicated for $8 \mathrm{~h} . \mathrm{ZrCl}_{4}(1.17 \mathrm{~g})$ and $\mathrm{H}_{2} \mathrm{BDC}(0.83 \mathrm{~g})$ were added to the GO solution and mixed until completely dissolved. The mixture was transferred into a $200 \mathrm{~mL}$ Teflon liner within a stainless-steel autoclave and heated at $120{ }^{\circ} \mathrm{C}$ for $24 \mathrm{~h}$. After the solvothermal reaction, the solution was cooled, centrifuged, and washed with DMF and methanol several times. Finally, the product was dried and kept dry until it was used.

Composite NF membranes were prepared with a PASA system [22] with some modifications (Figure S1). The pristine NF membranes were submerged and washed in MilliQ water for at least $5 \mathrm{~h}$. Different amounts of the UiO-66_GO nanocomposite $(5,10$, or $15 \mathrm{wt} \%$ of the pristine NF membrane) were dispersed in MilliQ water to achieve a consistent concentration of $0.25 \mathrm{~g} / \mathrm{L}$, and the dispersions were sonicated for $15 \mathrm{~min}$. Each of the solutions was filtered through an NF membrane $(D=76 \mathrm{~mm})$ in the stirred cell apparatus under a pressure of 5 bar. The composite membranes were dried in air at room temperature overnight, and then dried in a freeze dryer overnight and kept dry until use. The final composite NF membranes with 5, 10, and $15 \mathrm{wt} \%$ loadings of the UiO-66_GO nanocomposite were denoted as UiO66_GO/NF-5\%, UiO66_GO/NF-10\%, and UiO66_GO/NF-15\%, respectively.

\subsection{Characterization of UiO-66_GO Nanocomposite and Membranes}

Surface morphologies of the UiO-66_GO nanocomposite were observed by TEM (JEM-2010 F, JEOL, Tokyo, Japan) and SEM (SU9000, Hitachi, Tokyo, Japan). The functional groups in the composite material were identified by FTIR spectroscopy from 400 to $4000 \mathrm{~cm}^{-1}$, using $\mathrm{KBr}$ pellets (FTIR 4600, JASCO, Tokyo, Japan). Ultraviolet/visible (UV/Vis) absorption spectra of the UiO-66_GO nanocomposite were measured by a spectrophotometer (UV-2600, Shimadzu, Kyoto, Japan) to calculate its indirect band gap by the Tauc plot model [16].

The static water contact angle of the membrane surface was determined with a contact angle meter (Simage AUTO 100, Excimer Inc., Yokohama, Japan) to confirm their hydrophilicity. Three measures of surface roughness were measured by AFM (Asylum CypherS, Oxford Instruments, Abingdon, UK) with a scan area of $3 \times 3 \mu \mathrm{m}$. The measures were average roughness $\left(S_{\mathrm{a}}\right)$ and root mean square roughness $\left(S_{\mathrm{q}}\right)$, which are the average deviation and standard deviation of peaks and valleys, respectively, and the mean height difference between the highest peaks and lowest valleys $\left(S_{\mathrm{y}}\right)$. In addition, the membrane thickness (l) was manually measured by using a scale ruler.

Overall porosity $(\varepsilon)$ and mean pore radius $\left(r_{m}\right)$ of the membranes were calculated by the gravimetric method (Equation (1)) and the Guerout-Elford-Ferry model (Equation (2)), respectively [7].

$$
\varepsilon=\frac{m_{1}-m_{2}}{l A d_{w}}
$$




$$
r_{m}=\sqrt{\frac{(2.9-1.75 \varepsilon) 8 \eta l Q}{A \varepsilon P}}
$$

Here, $m_{1}$ and $m_{2}$ are the masses of the wet and dry membranes $(\mathrm{kg})$, respectively, $l$ is the membrane thickness $(\mathrm{m}), A$ is the membrane surface area $\left(\mathrm{m}^{2}\right), d_{w}$ is water density $\left(10^{3} \mathrm{~kg} / \mathrm{m}^{3}\right), \eta$ is water viscosity $\left(8.9 \times 10^{-9}\right.$ bar s), $Q$ is the volume flow rate $\left(\mathrm{m}^{3} / \mathrm{s}\right)$, and $P$ is the operational pressure (bar).

\subsection{Filtration Experiment}

The permeate flux of four membranes (pristine NF, UiO-66_GO/NF-5\%, UiO-66_GO/NF-10\%, and UiO-66_GO/NF-15\%) were measured in a dead-end cell filtration system filled with nitrogen gas as a pressure source (Figure S1). The membrane sheet was cut into a circle $76 \mathrm{~mm}$ in diameter with an effective area of approximately $41.2 \mathrm{~cm}^{2}$. Prior to the filtration experiment, each membrane was compacted under a pressure of 5 bar with MilliQ water for $30 \mathrm{~min}$ to obtain a steady-state flux. To determine the pure water flux, MilliQ water was filtered under a pressure of 4 bar and the permeate flux was recorded every $10 \mathrm{~min}$ for $1 \mathrm{~h}$. Then, the pure water flux $\left(J_{w 1}, \mathrm{~kg} / \mathrm{m}^{2} \mathrm{~h}\right.$ bar) was calculated by [7].

$$
J_{w 1}=\frac{M}{A t P}
$$

where $M$ is the weight of the permeate $(\mathrm{kg}), A$ is the membrane active surface $\left(\mathrm{m}^{2}\right), t$ is the permeation time (h), and $P$ is the operational pressure (bar).

In addition, to examine the stability of the composite membranes (UiO-66_GO/NF-5\%, UiO-66_GO/NF-10\%, and UiO-66_GO/NF-15\%), each composite membrane was washed with MilliQ five times and dried. The masses of the composite membranes before and after washing were determined to calculate the mass loss of the UiO-66_GO composite to indicate their stability.

To determine their flux recovery performance, immediately after pure water filtration $\left(J_{w 1}\right)$, MilliQ water was replaced with $50 \mathrm{mg} / \mathrm{L}$ SRHA as a model foulant, and it was filtered in an identical system for $3 \mathrm{~h}\left(J_{S R H A}\right)$. The fouled membrane was washed and kept in MilliQ water for $15 \mathrm{~min}$ and its pure water flux was determined again $\left(J_{w 2}\right)$. The anti-fouling properties of the pristine and composite membranes were quantified by the FRR [28].

$$
\operatorname{FRR}(\%)=100 \frac{J_{w 2}}{J_{w 1}}
$$

Here, $J_{w 1}$ and $J_{w 2}$ are the pure water fluxes $\left(\mathrm{kg} / \mathrm{m}^{2} \mathrm{~h}\right)$ before and after fouling, respectively. A higher $F R R$ indicates better fouling resistance.

To understand the fouling behavior better, the additional indicators $R_{r}, R_{i r}$, and $R_{t}$ were determined by Equations (5)-(7), respectively [29].

$$
\begin{aligned}
& R_{r}(\%)=100 \frac{J_{w 2}-J_{S R H A}}{J_{w 1}} \\
& R_{i r}(\%)=100 \frac{J_{w 1}-J_{w 2}}{J_{w 1}} \\
& R_{t}(\%)=100 \frac{J_{w 1}-J_{S R H A}}{J_{w 1}}
\end{aligned}
$$

$R_{r}$ indicates the proportion of fouling caused by concentration polarization. $R_{i r}$ indicates the proportion of fouling caused by adsorption or/and deposition of SRHA molecules on the membrane surface. $R_{t}$ is 
the sum of $R_{r}$ and $R_{i r}$, indicating the degree of total flux decline. In general, a lower ratio shows better fouling resistance.

To confirm how photocatalysis regenerated the composite membrane, after the filtration with SRHA solution for $3 \mathrm{~h}$, the fouled membrane was irradiated under UV light (wavelength, $254 \mathrm{~nm}$; intensity, $0.16 \mathrm{~W} / \mathrm{cm}^{2}$ ) for $1 \mathrm{~h}$. The membrane was then subjected to pure water filtration and FRR and $R_{i r}$ were calculated by Equations (4) and (6), respectively.

The separation performance of fresh UiO-66_GO/NF membranes was evaluated by rejection of DCF and CBZ with the same filtration apparatus. They were selected as model OMPs because they are among the most frequently detected OMPs in the aquatic environment [47]. Solutions of $1.0 \mathrm{mg} / \mathrm{L}$ of DCF and $\mathrm{CBZ}$ at $\mathrm{pH} 5$ were filtered by each of the UiO-66_GO/NF membranes for $2 \mathrm{~h}$ under a pressure of 4 bar. The residual concentrations were determined by high-performance liquid chromatography (Prominence UFLC, Shimadzu) equipped with a UV/Vis absorbance detector (SPD-20 UFLC, Shimadzu) and a C18 column of dimensions $4.6 \mathrm{~mm} \times 250 \mathrm{~mm} \times 5 \mu \mathrm{m}$ (Kinetex, Phenomenex, Torrance, CA, USA). To determine the DCF concentration, the oven temperature was $40{ }^{\circ} \mathrm{C}$ and the UV/Vis detector was operated at $276 \mathrm{~nm}$. The mobile phase was a mixture of methanol (75\%) and water $(25 \%)$ at a constant flow rate of $1 \mathrm{~mL} / \mathrm{min}$. To determine the CBZ concentration, the oven temperature was $40{ }^{\circ} \mathrm{C}$ and the detection wavelength was at $285 \mathrm{~nm}$. The mobile phase was a mixture of methanol (60\%) and water $(40 \%)$ at a constant flow rate of $0.6 \mathrm{~mL} / \mathrm{min}$. The relative errors of the measurements for DCF and CBZ were $2-12 \%$ and $0.7-7 \%$, respectively. Based on these measurements, the removal efficiencies of the OMPs were calculated by:

$$
\operatorname{Removal}(\%)=100 \frac{C_{0}-C_{p}}{C_{0}}
$$

where $C_{0}$ and $C_{p}$ are the initial and permeate concentrations $(\mathrm{mg} / \mathrm{L})$, respectively.

\section{Conclusions}

Photocatalytic NF membranes were fabricated by depositing a UiO-66_GO nanocomposite synthesized by a hydrothermal method on NF membranes by PASA to improve the water flux and anti-fouling properties. The UiO-66_GO nanocomposite at a loading of $15 \mathrm{wt} \%$ increased pure water flux by $187 \%$ compared with the pristine NF membrane flux by increasing the surface smoothness and hydrophilicity of the membrane surface. However, the $10 \mathrm{wt} \%$ loading of the UiO-66_GO composite was optimal because of its high flux improvement (169\%) and the good stability of the UiO-66_GO nanocomposite on the membrane surface. The UiO-66_GO/NF-10\% membrane also showed higher FRR $(80 \%)$ and lower $R_{i r}(20 \%)$ than did the pristine NF membrane, which were attributed to the increased hydrophilicity, surface smoothness, and charge repulsion. In addition, the composite membrane showed photocatalytic activity that degraded accumulated SRHA and increased $F R R$ to $98 \%$. The composite membrane also showed high solute rejection of DCF and CBZ, although we still need to measure the effects of photocatalytic activity of UiO-66_GO on solute rejection by the membrane and membrane lifetime. The UiO-66_GO nanocomposite is a promising additive for developing advanced photocatalytic NF membranes to tackle common problems in water treatment, such as limited flux, high energy consumption, and short membrane lifetime.

Supplementary Materials: The following materials are available online at http://www.mdpi.com/2073-4344/10/6/711/s1: Figure S1: Schematic of the preparation of UiO-66_GO/NF membrane; Figure S2: Water contact angle measurement; Figure S3: Images of the composite membrane before and after washing five times.

Author Contributions: Conceptualization, R.H., M.A., and C.Y.; methodology, R.H., M.A., and C.Y.; validation, R.H., M.A., and C.Y.; formal analysis, R.H., M.A., and C.Y.; investigation, R.H.; resources, C.Y.; data curation, R.H.; writing-original draft preparation, R.H.; writing-review and editing, R.H., M.A., and C.Y.; visualization, R.H., M.A., and C.Y.; supervision, M.A. and C.Y.; funding acquisition, C.Y. All authors have read and agreed to the published version of the manuscript. 
Funding: This research was funded by the Japan Society for the Promotion of Science (JSPS KAKENHI), grant number $18 \mathrm{H} 01566$.

Acknowledgments: Rina Heu would like to acknowledge financial support from the ASEAN University Network/Southeast Asia Engineering Education Development Network (AUN/SEED-Net) program of the Japan International Cooperation Agency (JICA). We also would like to thank the Ookayama and Suzukakedai Material Analysis Divisions of the Tokyo Institute of Technology, Japan for SEM and AFM observations, and Manami Miyamoto, a technician, and Yumi Namba, a secretary, for their support.

Conflicts of Interest: The authors declare no conflict of interest.

\section{References}

1. Lee, A.; Elam, J.W.; Darling, S.B. Membrane materials for water purification: Design, development, and application. Environ. Sci. Water Res. Technol. 2016, 2, 17-42. [CrossRef]

2. Eriksson, P. Nanofiltration extends the range of membrane filtration. Environ. Prog. Sustain. Energy 1988, 7, $58-62$. [CrossRef]

3. Plakas, K.V.; Karabelas, A.J. Removal of pesticides from water by NF and RO membranes-A review. DES 2012, 287, 255-265. [CrossRef]

4. Cyna, B.; Chagneau, G.; Bablon, G.; Tanghe, N. Two years of nanofiltration at the Méry-sur-Oise plant, France. Desalination 2002, 147, 69-75. [CrossRef]

5. Ventresque, C.; Gisclon, V.; Bablon, G.; Chagneau, G. An outstanding feat of modern technology: The Mery-sur-Oise nanofiltration treatment plant $\left(340,000 \mathrm{~m}^{3} / \mathrm{d}\right)$. Desalination 2000, 131, 1-16. [CrossRef]

6. Jiang, S.; Ladewig, B.P. Green synthesis of polymeric membranes: Recent advances and future prospects. Curr. Opin. Green Sustain. Chem. 2020, 21, 1-8. [CrossRef]

7. Safarpour, M.; Khataee, A.; Vatanpour, V. Preparation of a novel polyvinylidene fluoride (PVDF) ultrafiltration membrane modified with reduced graphene oxide/titanium dioxide $\left(\mathrm{TiO}_{2}\right)$ nanocomposite with enhanced hydrophilicity and antifouling properties. Ind. Eng. Chem. Res. 2014, 53, 13370-13382. [CrossRef]

8. Alpatova, A.; Kim, E.; Sun, X.; Hwang, G. Fabrication of porous polymeric nanocomposite membranes with enhanced anti-fouling properties: Effect of casting composition. J. Memb. Sci. 2013, 444, 449-460. [CrossRef]

9. Wu, G.; Gan, S.; Cui, L.; Xu, Y. Applied Surface Science Preparation and characterization of PES/TiO 2 composite membranes. Appl. Surf. Sci. 2008, 254, 7080-7086. [CrossRef]

10. Ma, J.; Guo, X.; Ying, Y.; Liu, D.; Zhong, C. Composite ultrafiltration membrane tailored by MOF @ GO with highly improved water purification performance. Chem. Eng. J. 2017, 313, 890-898. [CrossRef]

11. Denny, M.S.; Cohen, S.M. In situ modification of metal-organic frameworks in mixed-matrix membranes. Angew. Chemie Int. Ed. 2015, 54, 9029-9032. [CrossRef] [PubMed]

12. Li, J.R.; Sculley, J.; Zhou, H.C. Metal-organic frameworks for separations. Chem. Rev. 2012, 112, 869-932. [CrossRef] [PubMed]

13. Ahmed, I.; Jhung, S.H. Composites of metal-Organic frameworks: Preparation and application in adsorption. Biochem. Pharmacol. 2014, 17, 136-146. [CrossRef]

14. Awfa, D.; Ateia, M.; Fujii, M.; Johnson, M.S. Photodegradation of pharmaceuticals and personal care products in water treatment using carbonaceous-TiO 2 composites: A critical review of recent literature. Water Res. 2018, 142, 26-45. [CrossRef]

15. Awfa, D.; Ateia, M.; Fujii, M.; Yoshimura, C. Novel magnetic carbon nanotube-TiO 2 composites for solar light photocatalytic degradation of pharmaceuticals in the presence of natural organic matter. J. Water Process Eng. 2019, 31, 100836. [CrossRef]

16. Heu, R.; Ateia, M.; Awfa, D.; Punyapalakul, P.; Yoshimura, C. Photocatalytic Degradation of Organic Micropollutants in Water by Zr-MOF / GO Composites. J. Compos. Sci. 2020, 4, 54. [CrossRef]

17. Van der Bruggen, B.; Mänttäri, M.; Nyström, M. Drawbacks of applying nanofiltration and how to avoid them: A review. Sep. Purif. Technol. 2008, 63, 251-263. [CrossRef]

18. Fujioka, T.; Aizawa, H.; Kodamatani, H. Fouling substances causing variable rejection of a small and uncharged trace organic chemical by reverse osmosis membranes. Environ. Technol. Innov. 2020, 17, 100576. [CrossRef] 
19. Petit, C.; Bandosz, T.J. MOF-graphite oxide nanocomposites: Surface characterization and evaluation as adsorbents of ammonia. J. Mater. Chem. 2009, 19, 6521-6528. [CrossRef]

20. Safarpour, M.; Vatanpour, V.; Khataee, A.; Esmaeili, M. Development of a novel high flux and fouling-resistant thin film composite nanofiltration membrane by embedding reduced graphene oxide/ $/ \mathrm{TiO}_{2}$. Sep. Purif. Technol. 2015, 154, 96-107. [CrossRef]

21. Shen, J.N.; Yu, C.C.; Ruan, H.M.; Gao, C.J.; Van der Bruggen, B. Preparation and characterization of thin-film nanocomposite membranes embedded with poly(methyl methacrylate) hydrophobic modified multiwalled carbon nanotubes by interfacial polymerization. J. Memb. Sci. 2013, 442, 18-26. [CrossRef]

22. Ying, Y.; Liu, D.; Zhang, W.; Huang, H.; Yang, Q.; Zhong, C. High-Flux Graphene Oxide Membranes Intercalated by Metal-Organic Framework with Highly Selective Separation of Aqueous Organic Solution. ACS Appl. Mater. Interfaces 2017, 9, 1710-1718. [CrossRef] [PubMed]

23. Wu, H.; Mansouri, J.; Chen, V. Silica nanoparticles as carriers of antifouling ligands for PVDF ultrafiltration membranes. J. Memb. Sci. 2013, 433, 135-151. [CrossRef]

24. Vatanpour, V.; Madaeni, S.S.; Rajabi, L.; Zinadini, S.; Derakhshan, A.A. Boehmite nanoparticles as a new nanofiller for preparation of antifouling mixed matrix membranes. J. Memb. Sci. 2012, 401-402, 132-143. [CrossRef]

25. Fathizadeh, M.; Aroujalian, A.; Raisi, A. Effect of added NaX nano-zeolite into polyamide as a top thin layer of membrane on water flux and salt rejection in a reverse osmosis process. J. Memb. Sci. 2011, 375, 88-95. [CrossRef]

26. Mousa, H.M.; Alfadhel, H.; Ateia, M.; Gomaa, A.A.; Abdel-Jaber, G.T. Polysulfone-Iron Acetate/Polyamide Nanocomposite Membrane for Oil-Water Separation. Environ. Nanotechnol. Monit. Manag. 2020, 100314.

27. Van Der Bruggen, B.; Vandecasteele, C.; Van Gestel, T.; Doyenb, W.; Leysenb, R. Review of Pressure-Driven Membrane Processes. Environ. Prog. 2003, 22, 46-56. [CrossRef]

28. Kumar, M.; Gholamvand, Z.; Morrissey, A.; Nolan, K.; Ulbricht, M.; Lawler, J. Preparation and characterization of low fouling novel hybrid ultrafiltration membranes based on the blends of $\mathrm{GO}-\mathrm{TiO}_{2}$ nanocomposite and polysulfone for humic acid removal. J. Memb. Sci. 2016, 506, 38-49. [CrossRef]

29. Safarpour, M.; Vatanpour, V.; Khataee, A. Preparation and characterization of graphene oxide/TiO 2 blended PES nanofiltration membrane with improved antifouling and separation performance. Desalination 2016, 393, 65-78. [CrossRef]

30. Awfa, D.; Ateia, M.; Fujii, M.; Yoshimura, C. Photocatalytic degradation of organic micropollutants: Inhibition mechanisms by different fractions of natural organic matter. Water Res. 2020, 115643. [CrossRef]

31. Goosen, M.F.A.; Sablani, S.S.; Al-Hinai, H.; Al-Obeidani, S.; Al-Belushi, R.; Jackson, A. Fouling of reverse osmosis and ultrafiltration membranes: A critical review. Sep. Sci. Technol. 2005, 39, 2261-2297. [CrossRef]

32. Zhang, J.; Xu, Z.; Mai, W.; Min, C.; Zhou, B.; Shan, M.; Li, Y.; Yang, C.; Wang, Z.; Qian, X. Improved hydrophilicity, permeability, antifouling and mechanical performance of PVDF composite ultrafiltration membranes tailored by oxidized low-dimensional carbon nanomaterials. J. Mater. Chem. A 2013, 1, 3101-3111. [CrossRef]

33. Zinadini, S.; Zinatizadeh, A.A.; Rahimi, M.; Vatanpour, V.; Zangeneh, H. Preparation of a novel antifouling mixed matrix PES membrane by embedding graphene oxide nanoplates. J. Memb. Sci. 2014, 453, 292-301. [CrossRef]

34. Bernstein, R.; Belfer, S.; Freger, V. Bacterial attachment to RO membranes surface-modified by concentration-polarization-enhanced graft polymerization. Environ. Sci. Technol. 2011, 45, 5973-5980. [CrossRef]

35. Ateia, M.; Apul, O.G.; Shimizu, Y.; Muflihah, A.; Yoshimura, C.; Karanfil, T. Elucidating adsorptive fractions of natural organic matter on carbon nanotubes. Environ. Sci. Technol. 2017, 51, 7101-7110. [CrossRef]

36. Hebbar, R.S.; Isloor, A.M.; Ismail, A.F.; Shilton, S.J.; Obaid, A.; Fun, H.-K. Probing the morphology and anti-organic fouling behaviour of a polyetherimide membrane modified with hydrophilic organic acids as additives. New J. Chem. 2015, 39, 6141-6150. [CrossRef]

37. Ateia, M.; Alalm, M.G.; Awfa, D.; Johnson, M.S.; Yoshimura, C. Modeling the degradation and disinfection of water pollutants by photocatalysts and composites: A critical review. Sci. Total Environ. 2020, 698, 134197. [CrossRef]

38. Castarlenas, S.; Téllez, C.; Coronas, J. Gas separation with mixed matrix membranes obtained from MOF UiO-66graphite oxide hybrids. J. Memb. Sci. 2017, 526, 205-211. [CrossRef] 
39. Cai, N.; Larese-casanova, P. Sorption of carbamazepine by commercial graphene oxides: A comparative study with granular activated carbon and multiwalled carbon nanotubes. J. Colloid Interface Sci. 2014, 426, $152-161$. [CrossRef]

40. Chen, C.; Chen, D.; Xie, S.; Quan, H.; Luo, X.; Guo, L. Adsorption behaviors of organic micropollutants on zirconium metal—organic framework UiO-66: Analysis of surface interactions. ACS Appl. Mater. Interfaces 2017, 9, 41043-41054. [CrossRef]

41. Lin, Y.-L. Effects of organic, biological and colloidal fouling on the removal of pharmaceuticals and personal care products by nanofiltration and reverse osmosis membranes. J. Memb. Sci. 2017, 542, 342-351. [CrossRef]

42. Guan, Y.-F.; Qian, C.; Chen, W.; Huang, B.-C.; Wang, Y.-J.; Yu, H.-Q. Interaction between humic acid and protein in membrane fouling process: A spectroscopic insight. Water Res. 2018, 145, 146-152. [CrossRef] [PubMed]

43. Kincl, M.; Meleh, M.; Veber, M.; Vrecer, F. Study of physicochemical parameters affecting the release of diclofenac sodium from lipophilic matrix tablets. Acta Chim. Slov. 2004, 51, 409-425.

44. Moztahida, M.; Jang, J.; Nawaz, M.; Lim, S.; Sung, D. Effect of rGO loading on $\mathrm{Fe}_{3} \mathrm{O}_{4}$ : A visible light assisted catalyst material for carbamazepine degradation. Sci. Total Environ. 2019, 667, 741-750. [CrossRef] [PubMed]

45. Oleszczuk, P.; Pan, B.; Xing, B. Adsorption and desorption of oxytetracycline and carbamazepine by multiwalled carbon nanotubes. Environ. Sci. Technol. 2009, 43, 9167-9173. [CrossRef]

46. Liu, Y.; Wang, X.; Yang, H.; Xie, Y.F. Quantifying the influence of solute-membrane interactions on adsorption and rejection of pharmaceuticals by NF/RO membranes. J. Memb. Sci. 2018, 551, 37-46. [CrossRef]

47. Suriyanon, N.; Punyapalakul, P.; Ngamcharussrivichai, C. Mechanistic study of diclofenac and carbamazepine adsorption on functionalized silica-based porous materials. Chem. Eng. J. 2013, 214, 208-218. [CrossRef] 